\title{
SISTEMAS DE MANEJO E OS ESTOQUES DE CARBONO E NITROGÊNIO EM LATOSSOLO DE CERRADO COM A SUCESSÃO SOJA-MILHO(1)
}

\author{
Rafael de Souza Nunes ${ }^{(2)}$, André Alves de Castro Lopes ${ }^{(2)}$, Djalma Martinhão \\ Gomes de Sousa ${ }^{(3)} \&$ Ieda de Carvalho Mendes ${ }^{(3)}$
}

\begin{abstract}
RESUMO
Os estoques de $\mathrm{C}$ e $\mathrm{N}$ no solo são determinados pelo balanço entre adição e perda no sistema, sendo o preparo do solo e o sistema de culturas determinantes nesse processo. Este estudo teve por objetivo avaliar o efeito de sistemas de manejo do solo baseados em sistemas de preparo, plantas de cobertura e adubação fosfatada nos estoques de $\mathrm{C}$ e $\mathrm{N}$ em frações físicas da matéria orgânica do solo e na biomassa e respiração microbiana em um solo cultivado por 11 anos na sucessão soja-milho. O experimento foi iniciado em $1999 \mathrm{em}$ um Latossolo Vermelho argiloso com teor de $\mathrm{P}$ adequado para obtenção de 80 a $90 \%$ de rendimentos potenciais de culturas anuais. $O$ delineamento experimental foi o de blocos ao acaso com parcelas divididas, tendo três sistemas de manejo baseados em preparo do solo e plantas de cobertura (sistema de preparo convencional com milheto, sistema plantio direto com milheto e sistema plantio direto com mucuna-preta) nas parcelas e duas doses de $P\left(0\right.$ e $100 \mathrm{~kg} \mathrm{ha}^{-1}$ ano $^{-1}$ de $\mathrm{P}_{2} \mathrm{O}_{5}$ na forma de superfosfato triplo, aplicados no sulco de semeadura) nas subparcelas. Amostras de solo foram retiradas no enchimento de grãos da soja (março de 2010), nas camadas de 0-5, 5-10 e 10-20 cm de profundidade, e submetidas ao fracionamento físico da matéria orgânica do solo e a análises microbianas. $\mathrm{O}$ sistema plantio direto promoveu estratificação de C orgânico e $\mathrm{N}$ total, enquanto o preparo convencional promoveu distribuição mais homogênea na camada de 0 a $20 \mathrm{~cm}$ de profundidade. A adubação fosfatada por 11 anos promoveu acúmulo de $\mathrm{C}$ orgânico e $\mathrm{N}$ total em solos com adequada disponibilidade inicial de $P$, com relação àquele que não recebeu adubação com $P$, independentemente do sistema de preparo e das plantas de cobertura. $\mathrm{O}$ sistema plantio direto apresentou maior estoque de $\mathrm{C}$ orgânico e $\mathrm{N}$ total, maior $\mathrm{C}$ biomassa
\end{abstract}

\footnotetext{
(1) Recebido para publicação em 10 de agosto de 2010 e aprovado em 25 de março de 2011.

(2) Pós-Graduando do Programa de Pós-Graduação em Agronomia da Faculdade de Agronomia e Medicina Veterinária da UnB. Campus Universitário Darcy Ribeiro. Caixa Postal 04508, CEP 70910-900 Brasília (DF). E-mails: rafaelsouza_nunes@yahoo.com.br; andrealvesagronomo@yahoo.com.br

(3) Pesquisador, Embrapa Cerrados. BR 020, km 18, CEP 73310-970 Planaltina (DF). E-mails: dmgsousa@cpac.embrapa.br; mendesi@cpac.embrapa.br
} 
microbiana e menor respiração microbiana em relação ao sistema de preparo convencional, ambos tendo o milheto como planta de cobertura. Quando sob plantio direto, maior estoque de $\mathrm{C}$ orgânico e $\mathrm{N}$ total, semelhante $\mathrm{C}$ biomassa microbiana e maior respiração microbiana foram obtidos com o milheto como planta de cobertura, em relação à mucuna. A taxa de conversão do $\mathrm{C}$ adicionado pelas culturas em C orgânico do solo foi de 4,0,8,2 e 14,3 \% para sistema de preparo convencional com milheto, sistema plantio direto com milheto e com mucuna, respectivamente.

Termos de indexação: preparo convencional, plantio direto, plantas de cobertura, adubação fosfatada, fracionamento físico da matéria orgânica, biomassa microbiana.

\title{
SUMMARY: MANAGEMENT SYSTEMS AND THE CARBONAND NITROGEN STOCKS OF CERRADO OXISOL UNDER SOYBEAN-MAIZE SUCCESSION
}

\begin{abstract}
Carbon and $N$ stocks in soils are determined by the balance between addition and losses, and tillage and cropping systems are decisive in this process. This study aimed to evaluate the effect of soil management systems based on tillage, cover crops and $P$ fertilization on $C$ and $N$ stocks in physical fractions of the soil organic matter and on microbial biomass and respiration in a soil after 11 years under soybean-maize rotation. The experiment was initiated in 1999 in an Oxisol with adequate level of available P to obtain form 80 to $90 \%$ of potential yields of annual crops. The experiment was arranged in a split-plot design in randomized blocks, with three management systems based on soil tillage and cover crop (conventional tillage with pearl millet, no-tillage with pearl millet and no-tillage with velvet bean) assigned to the main plots and two Plevels ( 0 and $100 \mathrm{~kg} \mathrm{ha}^{-1} \mathrm{yr}^{-1}$ of $\mathrm{P}_{2} \mathrm{O}_{5}$ as triple superphosphate applied at sowing) in subplots. Soil samples were collected at the grain filling stage of soybean (March 2010), from the soil layers $0-5,5-10$ and 10-20 cm, and subjected to physical fractionation of organic matter and microbial analysis. The no-tillage system resulted in stratification of organic $C$ and $N$ while conventional tillage resulted in a more homogeneous distribution in the $0-20 \mathrm{~cm}$ layer. Phosphorus fertilization for 11 years led to an accumulation of organic $C$ and $N$ in the soil, regardless of tillage and cover crop systems. Higher stocks of organic C and total $N$, higher microbial biomass $C$ and lower microbial respiration were found under no-tillage than conventional tillage, both with pearl millet as cover crop. In the no-tillage systems, greater stocks of organic $C$ and total $N$, similar microbial biomass $C$ and higher microbial respiration were found with pearl millet as cover crop compared to velvet bean. The conversion rate of $C$ added by crops to soil organic C was 4.0, 8.2 and $14.3 \%$ for conventional tillage with pearl millet and no-tillage with pearl millet and with velvet bean, respectively.
\end{abstract}

Index terms: Conventional tillage, no-tillage, cover crops, phosphate fertilization, physical fractionation of organic matter, microbial biomass.

\section{INTRODUÇÃO}

A conversão de ecossistemas naturais em áreas cultivadas promove alteração nas taxas de adição e perdas efetivas de matéria orgânica do solo (MOS). O declínio ou acréscimo de MOS dependerá, para o mesmo ambiente edáfico, do tipo de manejo adotado (Bayer et al., 2000c); se esse manejo for mantido por longo período, os teores de MOS tendem a estabilizarse num novo equilíbrio (Bayer \& Mielniczuk, 1999).

Uma vez que são componentes da MOS, C e N têm sua dinâmica intimamente associada, diferindo, no entanto, quanto aos mecanismos de adição e perda no sistema (Bayer et al., 2000a,b). O C entra no sistema por meio da atividade fotossintética de plantas, o que demonstra a importância de sistemas de manejo altamente produtivos, que, associados a um manejo do solo adequado, podem promover aumentos consideráveis no estoque de MOS (Bayer at al., 2000b; Sisti et al., 2004). No caso dos solos do Cerrado, elevadas produtividades vegetais estão condicionadas principalmente à disponibilidade de $\mathrm{P}$ (Sousa \& Lobato, 2004), uma vez que esses solos apresentam teores originalmente muito baixos deste nutriente e elevada capacidade de adsorção à fase sólida, quando aplicado via fertilizante. Além disso, a taxa com que o $\mathrm{C}$ adicionado passa a compor a MOS é maior para o 
$\mathrm{C}$ do sistema radicular das plantas em relação àquele adicionado à superfície do solo (Balesdent \& Balabane, 1992), sobretudo em sistemas de baixa mobilidade do solo, como no sistema de plantio direto e pastagens fato que demonstra a importância de culturas com sistema radicular abundante, como as gramíneas. Por outro lado, as perdas de C estão relacionadas a erosão do solo e oxidação microbiana da MOS, sendo esses dois fenômenos minimizados pelo não revolvimento do solo, como ocorre no sistema plantio direto (Bayer at al., 2000b) e pastagens. Na região do Cerrado, a escassez de chuvas no inverno, limitando o uso de plantas de cobertura, e as elevadas temperaturas ao longo do ano, possibilitando elevada atividade microbiana, associadas ao monocultivo da soja, têm sido fatores limitantes do acúmulo de MOS nos mesmos moldes daqueles observados no Sul do País, mesmo em áreas sob plantio direto.

No que se refere ao $\mathrm{N}$, a entrada no sistema ocorre por meio da adubação e fixação biológica, enquanto as perdas estão relacionadas a fenômenos de erosão, lixiviação, desnitrificação e remoção pelas colheitas, sendo primordial um balanço positivo de $\mathrm{N}$ no sistema para que haja acúmulo desse nutriente e, por conseguinte, de MOS (Sisti et al., 2004; Diekow et al., 2005a). O correto manejo da adubação nitrogenada, associado ao uso de leguminosas na rotação de culturas, pode proporcionar essa condição. No entanto, rotação de culturas tendo soja como única leguminosa no sistema pode não promover acúmulo de $\mathrm{N}$ e MOS, visto que a grande taxa de exportação de N nos grãos faz com que essa cultura apresente balanço final de $\mathrm{N}$ próximo a zero (Alves et al., 2002). Isso demonstra a importância do uso de leguminosas como plantas de cobertura, capazes de adicionar $\mathrm{N}$ e fazer com que este possa ser incorporado à MOS (Sisti et al., 2004) ou assimilado pelas culturas subsequentes (Aita et al., 2001; Amado et al., 2001).

Os estoques de MOS são diretamente relacionados com a quantidade de $\mathrm{C}$ adicionada pelos sistemas de culturas, de modo que na maior parte dos trabalhos a variação desta é obtida por diferenças na adição de $\mathrm{N}$ via fertilizante ao sistema (Bayer et al., 2000a; Lovato et al., 2004). No entanto, uma vez que o $P$ é elemento limitante da produção agrícola (Sousa \& Lobato, 2004), o mesmo efeito ocorre, conforme observado por Sousa et al. (2010), que verificaram teores de MOS na camada de 0 a $20 \mathrm{~cm}$ variando de 24,0 a $37,0 \mathrm{~g} \mathrm{~kg}^{-1}$ devido a diferenças no aporte de resíduos vegetais, em função das fontes e doses de P utilizadas, em sistemas de cultivos anuais e com pastagem.

A fração particulada da MOS, por ser a mais sensível às alterações provocadas pelas práticas agrícolas, tem sido utilizada para avaliar alterações no balanço de $\mathrm{C}$ e $\mathrm{N}$ no solo (Conceição et al., 2005; Figueiredo et al., 2010). Além disso, propriedades microbianas respondem mais rapidamente às mudanças provocadas pelo preparo do solo e sucessão de culturas em relação a teores totais de $\mathrm{C}$ e $\mathrm{N}$ do solo (Powlson et al., 1987; Sparling, 1992; Balota et al., 1998; Matsuoka et al., 2003).

O objetivo deste estudo foi avaliar o efeito de sistemas de manejo do solo baseados em sistemas de preparo, culturas de cobertura e adubação fosfatada nos estoques de $\mathrm{C}$ e $\mathrm{N}$ em frações físicas da MOS e na biomassa e respiração microbiana, em um Latossolo do Cerrado cultivado na sucessão soja-milho.

\section{MATERIAL E MÉTODOS}

O estudo foi realizado na área experimental da Embrapa Cerrados, em Planaltina, DF (latitude de $15^{\circ} 36^{\prime} \mathrm{S}$ e longitude de $47^{\circ} 42^{\prime} \mathrm{W}$ ), altitude de $1.014 \mathrm{~m}$, com clima Cwa, precipitação pluvial média anual de $1.570 \mathrm{~mm}$ e temperatura média anual de $21,3{ }^{\circ} \mathrm{C}$. O relevo caracteriza-se como suave ondulado (3\%), a vegetação original é o Cerrado sentido estrito, e o solo, classificado como Latossolo Vermelho distrófico, com conteúdo médio de argila, silte e areia de 571,72 e $357 \mathrm{~g} \mathrm{~kg}^{-1}$, respectivamente, na camada de $0-20 \mathrm{~cm}$ de profundidade. $\mathrm{O}$ experimento tinha como objetivo principal a avaliação agronômica de fontes, modos e doses de aplicação de $\mathrm{P}$ em área de adequada fertilidade (10 mg dm${ }^{-3}$ de P - Mehlich-1, na camada de 0 a $20 \mathrm{~cm}$, por ocasião da instalação do experimento, em setembro de 1999), de acordo com recomendações para a região (Sousa \& Lobato, 2004).

A área foi convertida em sistema agrícola no ano de 1976, sendo utilizada para pastagem e produção de grãos por 20 anos. No ano de 1996 a área foi novamente preparada, quando se procedeu à correção dos níveis de acidez e fertilidade segundo recomendações de Sousa \& Lobato (2004), visando a alto rendimento de grãos. A área foi cultivada com soja em 1996/97 e 1997/98, com aplicação de $80 \mathrm{~kg} \mathrm{ha}^{-1}$ de $\mathrm{P}_{2} \mathrm{O}_{5}$ no sulco de plantio, $80 \mathrm{~kg} \mathrm{ha}^{-1}$ de $\mathrm{K}_{2} \mathrm{O}$ na forma de cloreto de potássio e $30 \mathrm{~kg} \mathrm{ha}^{-1}$ de $\mathrm{S}$ na forma de gesso, a lanço, simultaneamente ao plantio. Em 1998/99 foi cultivado o milho com a mesma adubação de K e S, além da adição de $150 \mathrm{~kg} \mathrm{ha}^{-1}$ de $\mathrm{N}$ na forma de ureia, mas sem aplicação de fertilizantes fosfatados. O objetivo desses três cultivos era conhecer a variabilidade da área para escolha do delineamento a ser utilizado e formar uma condição de alta fertilidade para estudo de manejo de $\mathrm{P}$ nessa condição.

O experimento teve início na safra 1999/00, adotando-se uma sucessão soja-milho com plantas de cobertura no inverno (de acordo com o tratamento), semeadas no final da estação chuvosa e roçadas no momento de pleno florescimento. Foram mantidas as adubações com N, Ke S dos três anos anteriores, e os tratamentos de P foram estabelecidos. Nos anos de 2008 e 2009 as plantas de cobertura receberam adubação de $45 \mathrm{~kg} \mathrm{ha}^{-1}$ de $\mathrm{N}$ na forma de uréia, visando maior produção de matéria seca. 
Os cultivos de soja e milho receberam irrigação suplementar por aspersão em situações de seca durante a estação chuvosa - fenômeno comum na região e denominado "veranico". A irrigação era definida com base em tensiômetros instalados nas parcelas a $20 \mathrm{~cm}$ de profundidade, quando estes apresentavam leitura maior que $45 \mathrm{~Pa}$. As plantas de cobertura no inverno receberam irrigação suplementar para desenvolvimento sem limitação de água.

O delineamento experimental utilizado foi o de blocos ao acaso com parcelas divididas; nas parcelas foram distribuídos aleatoriamente três sistemas de manejo: sistema de preparo convencional, constituído de uma aração e uma gradagem, realizadas imediatamente antes do plantio, tendo o milheto (Pennisetum glaucum) como planta de cobertura (SPC milheto); sistema plantio direto com milheto como planta de cobertura (SPD milheto); e sistema plantio direto com mucuna-preta (Mucuna aterrima) (SPD mucuna) como planta de cobertura. Nessas parcelas, os tratamentos de adubação fosfatada foram distribuídos aleatoriamente; as parcelas utilizadas na realização deste trabalho foram aquelas sem adubação fosfatada anual (P0) e com aplicação de $100 \mathrm{~kg} \mathrm{ha}^{-1}$ ano $^{-1}$ de $\mathrm{P}_{2} \mathrm{O}_{5}$ na forma de superfosfato triplo no sulco de semeadura (P100).

As amostras de solo foram coletadas em março de 2010 , no período de enchimento de grãos da soja $\left(11^{\circ}\right.$ cultivo), nas profundidades de 0 a 5,5 a 10 e 10 a $20 \mathrm{~cm}$, com trado de $5 \mathrm{~cm}$ de diâmetro, sendo uma amostra composta por cada parcela do experimento e cada amostra composta formada por 20 subamostras: quatro locais dentro de cada parcela $\mathrm{x}$ cinco subamostras por local (uma na linha e quatro nas entrelinhas, equidistantes). O solo foi homogeneizado e separado em duas porções: uma para análises químicas e outra para avaliação de parâmetros microbiológicos.

A porção de solo para análises químicas foi seca ao ar e passada em peneira de $2 \mathrm{~mm}$. Uma subamostra de aproximadamente $5 \mathrm{~g}$ foi moída em gral de porcelana até passar em peneira de $0,149 \mathrm{~mm}$, para avaliação de $\mathrm{C}$ orgânico total do solo (COT) e $\mathrm{N}$ total do solo (NT). Outra subamostra foi submetida ao fracionamento granulométrico da matéria orgânica, segundo Cambardella \& Elliot (1992): $20 \mathrm{~g}$ de solo foram colocados em frascos do tipo snap-cap de $250 \mathrm{~mL}$, adicionados de $80 \mathrm{~mL}$ de solução de hexametafosfato de sódio $\left(5 \mathrm{~g} \mathrm{~L}^{-1}\right)$, agitados por $16 \mathrm{~h}$ em agitador horizontal a 150 batidas por minuto; a suspensão foi passada em peneira de $53 \mu \mathrm{m}$, com auxílio de jatos de água. O material retido na peneira foi seco em estufa a $50{ }^{\circ} \mathrm{C}$ até atingir peso constante e moído em gral de porcelana até passar em peneira de $0,149 \mathrm{~mm}$, para avaliação do teor de C orgânico total da fração particulada, denominado C orgânico particulado (COP), e do teor de $\mathrm{N}$ total da fração particulada, denominado N particulado (NP). Os teores de COT e
COP foram determinados por combustão seca em analisador Perkin Elmer Series II CHNS/O 2400. Os teores de NT e NP foram determinados pelo método Kjeldhal (Embrapa 1997). Os teores de C orgânico associados aos minerais (COM) e de $\mathrm{N}$ associados aos minerais (NM) foram obtidos pela diferença entre os valores totais do solo sem dispersão química e aqueles obtidos nas frações particuladas após a dispersão $(\mathrm{COM}=\mathrm{COT}-\mathrm{COP} ; \mathrm{NM}=\mathrm{NT}-\mathrm{NP})$.

Também foram determinados os teores de $\mathrm{K}$ e $\mathrm{P}$, pelo extrator Mehlich-1, e saturação por bases (Embrapa, 1997). Considerando a média de todos os sistemas, o tratamento P0 apresentou valores de $0,36 \mathrm{cmol}_{\mathrm{c}} \mathrm{dm}^{-3}, 3 \mathrm{mg} \mathrm{dm}^{-3}$ e $39 \%$, e o P100, de $0,22 \mathrm{cmol}_{\mathrm{c}} \mathrm{dm}^{-3}, 13 \mathrm{mg} \mathrm{dm}{ }^{-3}$ e $41 \%$, para $\mathrm{K}, \mathrm{P}$ e saturação por bases, respectivamente.

A porção do solo para as análises microbianas foi passada em peneira de $4 \mathrm{~mm}$ e armazenada a uma temperatura de $7 \pm 3{ }^{\circ} \mathrm{C}$, até o momento de realização das análises. O C da biomassa microbiana (CBM) foi determinado pelo método de fumigação-extração, utilizando-se o procedimento descrito por Vance et al. (1987). A respiração microbiana foi obtida pela medição de $\mathrm{CO}_{2}$ liberado das amostras não fumigadas durante o período de pré-incubação das amostras destinadas à determinação do CBM (7 dias). Foi determinado o quociente metabólico, pela divisão da respiração microbiana pelo CBM, e o quociente microbiano, pela divisão do CBM pelo COT.

O solo, em todos os tratamentos, foi analisado quanto à densidade (Quadro 1) a partir da coleta de amostras de solo indeformada com anel de $5 \mathrm{~cm}$ de diâmetro e $100 \mathrm{~cm}^{-3}$, em três pontos dentro de cada parcela, nas profundidades de 0 a 5,5 a 10 e 10 a $20 \mathrm{~cm}$, tomando-se, para cada profundidade, a média dos três pontos para compor o valor de densidade da parcela. Uma vez que não foi encontrada diferença significativa para a densidade entre os tratamentos

\begin{tabular}{|c|c|c|c|c|}
\hline \multirow{2}{*}{$\begin{array}{l}\text { Sistema de } \\
\text { manejo }\end{array}$} & \multirow{2}{*}{$\begin{array}{l}\text { Dose de } \\
\text { fósforo }\end{array}$} & \multicolumn{3}{|c|}{ Profundidade $(\mathrm{cm})$} \\
\hline & & $0-5$ & $5-10$ & $10-20$ \\
\hline \multirow[b]{2}{*}{ SPC milheto } & \multirow[b]{2}{*}{$\mathrm{P} \cap$} & \multicolumn{3}{|c|}{$-\mathrm{g} \mathrm{cm}^{-3}$} \\
\hline & & $1,01^{\mathrm{ns}}$ & $1,03^{\mathrm{ns}}$ & $0,99^{\mathrm{ns}}$ \\
\hline SPD milheto & P0 & 0,99 & 1,02 & 0,98 \\
\hline SPD mucuna & P0 & 1,00 & 1,02 & 0,98 \\
\hline SPC milheto & P100 & 1,00 & 1,04 & 0,99 \\
\hline SPD milheto & P100 & 1,01 & 1,02 & 0,99 \\
\hline SPD mucuna & P100 & 1,01 & 1,03 & 0,99 \\
\hline
\end{tabular}

SPC: sistema de preparo convencional, SPD: sistema plantio direto. P0: 0 e P100: $100 \mathrm{~kg} \mathrm{ha}^{-1} \mathrm{ano}^{-1}$ de $\mathrm{P}_{2} \mathrm{O}_{5}$ na forma de superfosfato triplo aplicado no sulco de semeadura. ns: não significativo pelo teste de Student $(p<0,05)$. 
utilizados no presente estudo, os estoques de C e N foram calculados em camadas equivalentes de solo, que leva em consideração a espessura da camada e a densidade do solo. Os estoques da camada de 0-20 cm foram obtidos a partir do somatório dos estoques de cada camada.

As adições de $\mathrm{C}$ pelas culturas no período do experimento foram calculadas com base na produção de grãos e avaliação de matéria seca das plantas de cobertura. Para o $\mathrm{C}$ adicionado pelas culturas de soja e milho, considerou-se a relação entre matéria seca total de parte aérea (folha + haste/colmo + grãos) e de grãos, chamada índice de colheita, que pode variar entre 40 e 50 \% (Bernardon, 2005; Kuss et al., 2008), utilizando-se para este trabalho o valor de $50 \%$, ou seja, a matéria seca de grãos corresponde a $50 \%$ do total de matéria seca de parte aérea produzido pela planta, sendo o restante folhas, hastes ou colmo, de acordo com a cultura. Assim, para cada $1 \mathrm{Mg} \mathrm{ha}^{-1}$ de grãos produzidos, estimou-se em $1 \mathrm{Mg} \mathrm{ha}^{-1}$ de MS adicionada pela parte aérea. Para o C adicionado pelas plantas de cobertura, foi feita avaliação de matéria seca de parte aérea coletada em $2 \mathrm{~m}^{2}$ por parcela (duas avaliações com quadrado de $1 \mathrm{~m}^{2}$ ) imediatamente antes da roçagem, no momento de pleno florescimento. Considerou-se uma contribuição média do sistema radicular de $30 \%$ do total de matéria seca produzida pelas culturas principais e plantas de cobertura (Balesdent \& Balabane, 1992; Bolinder et al., 1997; Bayer et al., 2000c; Lovato et al., 2004; Costa et al., 2008). Os cálculos de adições de $\mathrm{C}$ foram realizados considerando um teor médio de $40 \%$ desse elemento na matéria seca das culturas principais e plantas de cobertura (Aita et al., 1994; Spagnollo et al., 2002; Lovato et al., 2004; Costa et al., 2008).

Nas avaliações de distribuição em profundidade no solo foi utilizado o seguinte modelo:

$$
\begin{aligned}
\text { Yijk } & =\mu+\mathrm{Bj}+\mathrm{Si}+\text { Erro } i j+\mathrm{Dk}+(\mathrm{SD}) \mathrm{ik}+\text { Erro ijk } \\
& +\mathrm{Pl}+(\mathrm{PS}) \mathrm{il}+\mathrm{PD} \mathrm{kl}+\mathrm{PSD} \mathrm{ikl}+\text { Erro ijkl }
\end{aligned}
$$

em que $\mu=$ média geral dos dados; $B=\operatorname{bloco}(j=1,2,3)$; $\mathrm{S}=$ sistema de manejo $(\mathrm{i}=1,2) ; \mathrm{D}=$ dose de $\mathrm{P}(\mathrm{k}=$ $1,2) ; \mathrm{P}=$ profundidade $(1=1,2,3) ;$ Erro $=$ erro experimental.

Para as avaliações que não envolviam profundidade (estoque de $\mathrm{C}$ e N no solo, parâmetros microbiológicos como uma média ponderada de todas as camadas de solo e adição de C pela cultura principal e plantas de cobertura), foi utilizado o seguinte modelo:

$$
\text { Yijk }=\mu+B j+S i+\text { Erro } i j+D k+(S D) i k+\text { Erro ijk, }
$$

em que $\mu=$ média geral dos dados; $B=\operatorname{bloco}(j=1,2,3)$; $\mathrm{S}=$ sistema de manejo $(\mathrm{i}=1,2,3) ; \mathrm{D}=$ dose de $\mathrm{P}(\mathrm{k}=$ 1,2); Erro = erro experimental.

A análise de variância foi feita considerando o modelo misto de máxima verossimilhança restrita via PROC MIXED do SAS 9.1; quando ela apontou significância, o teste de hipótese de Student (t) $(\mathrm{p}<0,05)$ foi utilizado para distinção das médias.

\section{RESULTADOS E DISCUSSÃO}

Os efeitos dos sistemas de manejo e doses de $\mathrm{P}$ na distribuição dos teores de COT e NT na camada de 0$20 \mathrm{~cm}$ são apresentados na figura 1 . Os teores de COP, COM, NP e NM apresentaram a mesma tendência de distribuição observadas para os teores totais desses elementos, razão pela qual não foram apresentados.

Observou-se interação ( $p<0,05)$ entre sistemas, dose e profundidade (Figura 1). Nos tratamentos sob SPD, para as duas doses de P, os teores de COT e NT concentraram-se na camada superior e decresceram em profundidade. Essa estratificação em SPD tem sido comum e é originada pela deposição superficial

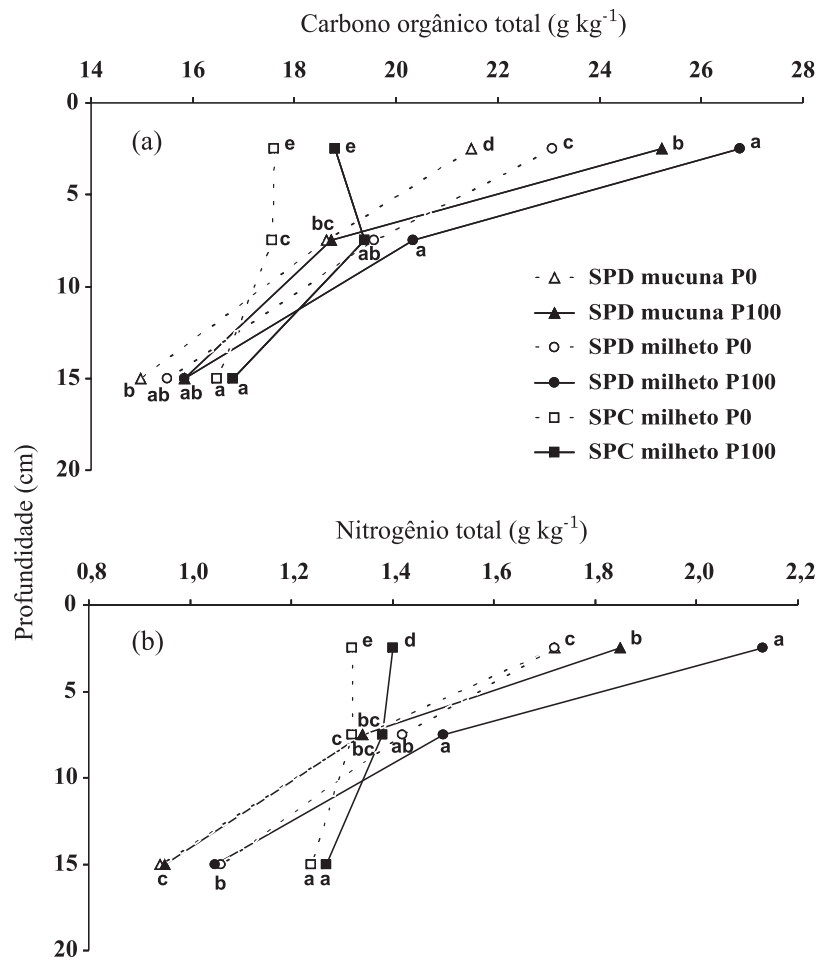

Figura 1. Distribuição de C orgânico total (a) e N total (b) na camada de 0-20 cm de um Latossolo Vermelho argiloso cultivado por 11 anos na sucessão soja-milho, sob três sistemas de manejo (sistema de preparo convencional com milheto - SPC milheto, sistema plantio direto com milheto - SPD milheto e sistema plantio direto com mucuna - SPD mucuna) e duas doses de fósforo (P0 - 0 e $\mathrm{P} 100$ - $100 \mathrm{~kg} \mathrm{ha}^{-1}$ ano $^{-1}$ de $\mathrm{P}_{2} \mathrm{O}_{5}$ na forma de superfosfato triplo aplicado no sulco de semeadura). Médias com letras iguais em uma mesma profundidade não diferem entre si pelo teste de Student $(p<0,05)$. 
de resíduo vegetal de parte aérea, bem como pelo crescimento radicular mais pronunciado em camadas superficiais, inclusive de espécies gramíneas, como o milho (Silva et al., 2000; Waisel et al., 2002; Costa et al., 2009). Por outro lado, para o SPC milheto, os teores foram semelhantes em todas as profundidades. Isso deve-se ao efeito do revolvimento com arado de discos e grade niveladora, que promove homogeneização na camada de 0 a $20 \mathrm{~cm}$, resultando, inclusive, em maiores teores de NT na camada de 10-20 no SPC, em relação aos tratamentos sob SPD.

Os estoques dos compartimentos de $\mathrm{C}$ e $\mathrm{N}$ foram influenciados significativamente pelos sistemas de manejo e doses de $\mathrm{P}$, tendo sido observada interação apenas para COP e relação COP/COT (Quadro 2).

Na comparação entre doses de P, observaram-se maiores estoques em quase todas as características avaliadas, com exceção de NM, nos tratamentos com aplicação de $100 \mathrm{~kg} \mathrm{ha}^{-1}$ ano $^{-1}$ de $\mathrm{P}_{2} \mathrm{O}_{5}$ na forma de superfosfato triplo (P100), em relação aos tratamentos sem aplicação de $\mathrm{P}$ (P0) (Quadro 2). Isso deve-se à maior produção de biomassa vegetal (Quadro 3) pelas culturas de soja, milho, milheto e mucuna quando adubadas com $\mathrm{P}$, mesmo em área de disponibilidade inicial de $\mathrm{P}$ adequada, como a do presente estudo (10,0 mg dm ${ }^{-3}$ de P - Mehlich-1, na camada de 0 a $20 \mathrm{~cm}$ ). Além disso, com o passar dos anos de cultivo, as diferenças de produção entre P100 e P0 aumentaram, devido à redução na disponibilidade de $\mathrm{P}$ provocada pela exportação nos grãos sem reposição no tratamento P0. O teor médio de $\mathrm{P}-$ Mehlich-1, após 11 anos de cultivo, dos tratamentos sem reposição de $\mathrm{P}$ (P0) foi de $3 \mathrm{mg} \mathrm{dm}^{-3}$, considerado muito baixo por Sousa \& Lobato (2004), ao passo que nos tratamentos com adição de $100 \mathrm{~kg} \mathrm{ha}^{-1}$ ano $^{-1}$ de $\mathrm{P}_{2} \mathrm{O}_{5}$ na forma de superfosfato triplo o teor médio de $\mathrm{P}$ - Mehlich-1 foi de $13 \mathrm{mg} \mathrm{dm}{ }^{-3}$, considerado alto. Lovato et al. (2004) também observaram que o aumento no estoque de $\mathrm{C}$, mesmo em SPD, é muito dependente da quantidade de $\mathrm{C}$ adicionada pelos sistemas de culturas, enquanto Bayer et al. (2000a) observaram grandes variações na taxa de sequestro de C em SPD $\left(0,13\right.$ a $0,97 \mathrm{Mg} \mathrm{ha}^{-1}$ ano $^{-1}$ ), diretamente relacionadas com o aporte anual de C. Sousa et al. (2010) verificaram teores de MOS na camada de 0 a $20 \mathrm{~cm}$ variando de 24,0 a $37,0 \mathrm{~g} \mathrm{~kg}^{-1}$ devido a diferenças no aporte de resíduos vegetais em função das fontes e doses de P utilizadas, em sistemas de cultivos anuais e com pastagem. Assim, nos sistemas com o tratamento P100 há maior produção de biomassa vegetal e, portanto, maior incorporação no solo de $\mathrm{C}$ pela fotossíntese e de $\mathrm{N}$ pela fixação biológica da soja e mucuna, além da maior absorção de $\mathrm{N}$ do solo previamente incorporado por essa via ou adicionado pelo fertilizante nitrogenado, em razão da maior demanda e do sistema radicular mais profundo, diminuindo possíveis perdas por lixiviação de nitrato, em comparação aos sistemas com tratamento P0. Os estoques de NM semelhantes para as duas doses de $\mathrm{P}$ indicam a pouca sensibilidade dessa fração às alterações provocadas pelas práticas agrícolas (Conceição et al., 2005).

$\mathrm{Na}$ comparação entre sistemas, observaram-se maiores estoques de COT e COP na sequência decrescente: SPD milheto > SPD mucuna > SPC milheto. Os maiores estoques nos sistemas envolvendo o SPD em relação ao SPC estão relacionados, principalmente, com a redução da taxa de decomposição microbiana devido à manutenção da estrutura do solo, que confere

Quadro 2. Estoques de C orgânico total (COT), C orgânico particulado (COP), C orgânico associado aos minerais (COM), relação COP/COT, $\mathrm{N}$ total (NT), $\mathrm{N}$ particulado (NP), $\mathrm{N}$ associado aos minerais (NM) e relação NP/NT na camada de 0-20 cm de um Latossolo Vermelho argiloso cultivado por 11 anos na sucessão soja-milho, sob três sistemas de manejo e duas doses de fósforo

\begin{tabular}{|c|c|c|c|c|c|c|c|c|c|}
\hline Sistema de manejo & Dose de fósforo & COT & COP & COM & COP/ COT & NT & NP & $\mathbf{N M}$ & $\mathbf{N P} / \mathbf{N T}$ \\
\hline & & $\longrightarrow$ & $\mathrm{Mg} \mathrm{ha}^{-1}$ & - & $\%$ & $\longrightarrow$ & $\mathrm{kg} \mathrm{ha}^{-1}$ & - & $\%$ \\
\hline SPC milheto & P0 & 34,36 & $2,59 \mathrm{c}$ & 31,77 & $7,6 \mathrm{c}$ & 2.574 & 168 & 2.407 & 6,5 \\
\hline SPD milheto & $\mathrm{P0}$ & 36,55 & $4,31 \mathrm{~b}$ & 32,25 & $11,8 \mathrm{~b}$ & 2.613 & 314 & 2.299 & 12,0 \\
\hline SPD mucuna & $\mathrm{P0}$ & 34,92 & $4,29 \mathrm{~b}$ & 30,63 & $12,3 \mathrm{~b}$ & 2.468 & 279 & 2.189 & 11,3 \\
\hline SPC milheto & $\mathrm{P} 100$ & 36,09 & $4,12 \mathrm{~b}$ & 31,98 & $11,4 \mathrm{~b}$ & 2.663 & 277 & 2.387 & 10,4 \\
\hline SPD milheto & $\mathrm{P} 100$ & 39,57 & 5,72 a & 33,85 & 14,5 a & 2.876 & 355 & 2.521 & 12,3 \\
\hline SPD mucuna & $\mathrm{P} 100$ & 38,02 & $4,61 \mathrm{~b}$ & 33,41 & $12,1 \mathrm{~b}$ & 2.559 & 321 & 2.238 & 12,5 \\
\hline \multicolumn{10}{|l|}{ Média de sistema } \\
\hline SPC milheto & & $35,23 \mathrm{c}$ & $3,35 \mathrm{c}$ & $31,87 \mathrm{a}$ & $9,5 \mathrm{~b}$ & $2.619 \mathrm{~b}$ & $222 \mathrm{~b}$ & $2.397 \mathrm{a}$ & $8,5 \mathrm{~b}$ \\
\hline SPD milheto & & $38,06 \mathrm{a}$ & $5,01 \mathrm{a}$ & $33,05 \mathrm{a}$ & $13,1 \mathrm{a}$ & $2.745 \mathrm{a}$ & $335 \mathrm{a}$ & $2.410 \mathrm{a}$ & $12,2 \mathrm{a}$ \\
\hline SPD mucuna & & $36,47 \mathrm{~b}$ & $4,45 \mathrm{~b}$ & $32,02 \mathrm{a}$ & $12,2 \mathrm{a}$ & $2.513 \mathrm{~b}$ & $300 \mathrm{a}$ & $2.214 \mathrm{~b}$ & $11,9 \mathrm{a}$ \\
\hline \multicolumn{10}{|l|}{ Média de dose } \\
\hline P0 & & $35,28 \mathrm{~b}$ & $3,73 \mathrm{~b}$ & $31,55 \mathrm{~b}$ & $10,5 \mathrm{~b}$ & $2.552 \mathrm{~b}$ & $253 \mathrm{~b}$ & $2.298 \mathrm{a}$ & $9,9 \mathrm{~b}$ \\
\hline $\mathrm{P} 100$ & & 37,89 a & $4,81 \mathrm{a}$ & $33,08 \mathrm{a}$ & $12,7 \mathrm{a}$ & $2.699 \mathrm{a}$ & $318 \mathrm{a}$ & $2.382 \mathrm{a}$ & $11,8 \mathrm{a}$ \\
\hline
\end{tabular}

SPC: sistema de preparo convencional, SPD: sistema plantio direto. P0: 0 e P100: $100 \mathrm{~kg}^{\mathrm{ha}^{-1}}$ ano $^{-1} \mathrm{de}_{2} \mathrm{O}_{5}$ na forma de superfosfato triplo aplicado no sulco de semeadura. Médias seguidas da mesma letra na coluna não diferem entre si pelo teste de Student $(\mathrm{p}<0,05)$. 
Quadro 3. Estimativa da adição total de C pela cultura principal e de cobertura em um Latossolo Vermelho argiloso durante 11 anos de cultivo na sucessão soja-milho, sob três sistemas de manejo e duas doses de fósforo

\begin{tabular}{lcccc}
\hline Sistema de manejo & Dose de fósforo & Cultura principal & Planta de cobertura & Total \\
\hline & & & Mg ha $^{-1} \mathrm{de} \mathrm{C}$ & 12,41 \\
SPC milheto & P0 & 20,83 & 14,70 & 33,23 \\
SPD milheto & P0 & 22,95 & 10,86 & 33,65 \\
SPD mucuna & P0 & 22,87 & 37,91 & 77,04 \\
SPC milheto & P100 & 39,13 & 36,24 & 74,60 \\
SPD milheto & P100 & 38,37 & 17,54 & 55,40 \\
SPD mucuna & P100 & 37,86 & $25,16 \mathrm{a}$ & $55,14 \mathrm{a}$ \\
Média de sistema & & $29,98 \mathrm{a}$ & $25,47 \mathrm{a}$ & $56,12 \mathrm{a}$ \\
SPC milheto & & $30,66 \mathrm{a}$ & $14,20 \mathrm{~b}$ & $44,56 \mathrm{~b}$ \\
SPD milheto & & $30,37 \mathrm{a}$ & $12,65 \mathrm{~b}$ & $34,87 \mathrm{~b}$ \\
SPD mucuna & & $22,22 \mathrm{~b}$ & $30,56 \mathrm{a}$ & $69,01 \mathrm{a}$ \\
Média de dose & & $38,45 \mathrm{a}$ & \\
P0 & & & & \\
P100 & & & & \\
\hline
\end{tabular}

SPC: sistema de preparo convencional, SPD: sistema plantio direto. P0: 0 e P100: $100 \mathrm{~kg} \mathrm{ha}^{-1} \mathrm{ano}^{-1}$ de $\mathrm{P}_{2} \mathrm{O}_{5}$ na forma de superfosfato triplo aplicado no sulco de semeadura. Médias seguidas da mesma letra na coluna não diferem entre si pelo teste de Student $(\mathrm{p}<0,05)$.

proteção física e química à MOS contra o acesso de microrganismos e suas enzimas (Burns, 1982; Hassink \& Whitmore, 1997). Além disso, maior produção de biomassa radicular de milho (Costa et al., 2009) e menores perdas de MOS por erosão (Hernani et al., 1999) têm sido relatadas em SPD em relação ao SPC. Dessa forma, mesmo utilizando como planta de cobertura a mucuna, com menor produção de biomassa vegetal em relação ao milheto (Quadro 3), o SPD apresentou maiores estoques de COT e COP em relação ao SPC, corroborando outros estudos também conduzidos na região do Cerrado (Corazza et al., 1999; Bayer et al., 2006; Jantalia et al., 2007).

Nos sistemas sob SPD, mas com diferentes plantas de cobertura, os estoques de COT e COP obedeceram à mesma lógica utilizada para a dose de $\mathrm{P}$, onde o maior aporte de biomassa vegetal na área com milheto resultou em maiores estoques (Quadro 2). Uma vez que as mesmas quantidades de $\mathrm{C}$ foram adicionadas pelas culturas principais para a mesma dose de $\mathrm{P}$ (Quadro 3), conclui-se que o diferencial de aporte de $\mathrm{C}$ entre SPD milheto e SPD mucuna foi a planta de cobertura. Isso demonstra a importância da utilização de gramíneas para promover acúmulo de $\mathrm{C}$ no solo na região do Cerrado. Costa et al. (2008), avaliando o estoque de COT e as emissões de $\mathrm{CO}_{2}$ em Argissolo Vermelho do Rio Grande do Sul em função de sistemas de preparo (SPD e SPC), culturas (somente gramíneas e leguminosa/gramínea) e adubação com $\mathrm{N}$, observaram que tanto o solo manejado em SPC, independentemente do sistema de culturas e adubação, como aquele em SPD, mas com baixo aporte de resíduos vegetais, proporcionaram balanço negativo de $\mathrm{C}$, representando perda líquida de $\mathrm{CO}_{2}$ para a atmosfera.
Em relação ao SPC milheto, os ganhos de COT no SPD foram da ordem de 8,0 e 3,5 \% para SPD milheto e SPD mucuna, respectivamente, enquanto para o COP esses ganhos foram de 49,5 e 32,7\% (Quadro 2). Na comparação entre SPD mucuna e SPD milheto, os ganhos do tratamento com milheto foram da ordem de 4,4 e 12,6\%, respectivamente para COT e COP. Isso demonstra a sensibilidade da fração particulada do C orgânico do solo em distinguir sistemas de manejo, conforme relatado em diversos trabalhos (Freixo et al., 2002; Diekow et al., 2005b), enquadrando-a como importante parâmetro de avaliação da qualidade do solo (Conceição et al., 2005; Vieira et al., 2007).

Não foram observados efeitos dos sistemas de manejo nos estoques de COM (Quadro 2). Isso devese à natureza dessa fração do C orgânico, que, por constituir-se de interações com as argilas do solo, é a mais estável no sistema, respondendo de maneira lenta aos efeitos de manejo de preparo de solo e culturas, especialmente nos solos argilosos e muito argilosos (Diekow et al., 2005b; Figueiredo et al., 2010). No entanto, vale ressaltar que parece haver tendência de comportamento diferenciado do SPD mucuna em relação ao SPD milheto para as doses de $\mathrm{P}$, uma vez que a diferença nos estoques de COM na área que não recebia adubação fosfatada, em relação àquela que recebia anualmente, foi maior no SPD mucuna em comparação com o SPD milheto. Possivelmente, a favorável relação $\mathrm{C} / \mathrm{N}$ da mucuna estimula a atividade microbiana, sem, no entanto, fornecer substrato lábil suficiente para a manutenção desta, que utilizaria pequena fração do COM antes de reduzir a atividade por escassez de alimento. Esse fenômeno, durante 
11 anos, pode ter ocasionado as diferenças observadas nos estoques de COM no tratamento $\mathrm{P} 0$ com milheto ou mucuna sob SPD.

A fração particulada da MOS, por ser aquela mais sensível às alterações provocadas pelas práticas agrícolas, tem sido utilizada para avaliar alterações no balanço de $\mathrm{C}$ e $\mathrm{N}$ no solo (Conceição et al., 2005; Figueiredo et al., 2010). Além disso, diversos índices relacionando as frações da MOS têm sido utilizados para comparação de sistemas de manejo, com resultados mais satisfatórios do que as frações isoladamente (Diekow et al., 2005b; Vieira et al., 2007). Neste trabalho, tanto o estoque de COP quanto a sua participação no COT (COP/COT) apresentaram interação $(\mathrm{p}<0,05)$ sistema $\mathrm{x}$ dose, estabelecendo SPD milheto P100 como a melhor condição e SPC milheto P0 como a pior, tendo os demais tratamentos apresentado posição intermediária e não diferindo entre si (Quadro 2). Assim, esses parâmetros foram mais sensíveis, em relação ao estoque de COT ou COM, às mudanças ocasionadas pelo manejo e poderiam ser usados como indicadores de qualidade do solo no que se refere à MOS.

Os efeitos dos sistemas nos estoques de $\mathrm{N}$ no solo diferiram do comportamento verificado para $\mathrm{C}$ (Quadro 2). Para o NT, SPD milheto apresentou estoque significativamente maior, seguido de SPC milheto e SPD mucuna, que não diferiram entre si. $\mathrm{Na}$ comparação entre SPD e SPC, ambos tendo o milheto como planta de cobertura, os resultados demonstram a capacidade do SPD em acumular NT, que, por ser um componente da MOS, tem sua dinâmica associada a esta (Bayer et al., 2000a,b; Lovato et al., 2004), de modo que os mecanismos que permitem acúmulo de MOS serão também responsáveis por permitir acúmulos de NT no solo. Além disso, redução de perdas de MOS por erosão (Hernani et al., 1999) e aumento na CTC (Bayer \& Mielniczuk, 1999), proporcionando retenção de $\mathrm{NH}_{4}{ }^{+}$, são os demais fatores que podem permitir maior acúmulo de $\mathrm{N}$ em solos sob SPD em relação ao SPC. Jantalia et al. (2007), em Latossolo de Cerrado cultivado por 20 anos sob SPD, observaram estoques de NT $24 \%$ maiores em relação ao SPC.

Por outro lado, na comparação entre SPD mucuna e SPD milheto, o menor estoque de NT na área com mucuna foi contrastante com aquilo que se observa na literatura, onde a incorporação de leguminosas no sistema favorece o acúmulo de C e N (Bayer et al., 2000a,b,c; Sisti et al., 2004; Costa et al., 2008), sendo inclusive importante fonte de $\mathrm{N}$ para a cultura subsequente (Lovato et al., 2004; Weber \& Mielniczuk, 2009). Aita et al. (2001) não observaram ganhos de produtividade de milho com aplicações de 0,80 e $160 \mathrm{~kg} \mathrm{ha}^{-1}$ de $\mathrm{N}$, quando cultivado após ervilhaca comum e tremoço-azul em Argissolo Vermelho do Rio Grande do Sul. Lovato et al. (2004) observaram aumentos da produção de milho e nos estoques de $\mathrm{C} \mathrm{e}$ $\mathrm{N}$ no solo em Argissolo Vermelho do Rio Grande do
Sul em função da adoção de SPD e incorporação de leguminosas como ervilhaca e caupi no sistema, em área inicialmente degradada por prática agrícola inadequada.

O uso de sucessão soja-milho, com elevada produção de soja (média para os cinco cultivos realizados no período e em todos os tratamentos de $2.773 \mathrm{~kg} \mathrm{ha}^{-1}$ ), as adubações com $\mathrm{N}$ no milho (150 kg ha-1 de $\mathrm{N}$ e produção média para os cinco cultivos realizados no período e em todos os tratamentos de $8.893 \mathrm{~kg} \mathrm{ha}^{-1}$ ) e as adubações com $\mathrm{N}$ na planta de cobertura em 2008 e 2009 (45 kg ha ${ }^{-1}$ de N) podem ter fornecido quantidade de $\mathrm{N}$ ao sistema suficiente para limitar o impacto da incorporação pela fixação biológica do $\mathrm{N}$ pela mucuna. A maior ciclagem de $\mathrm{N}$ e produção de biomassa radicular mais profunda podem ter permitido ao milheto maior manutenção do $\mathrm{N}$ na camada de 0 $20 \mathrm{~cm}$ analisada no presente estudo. Além disso, quando a palhada de mucuna permanece na superfície do solo, que foi a condição do SPD mucuna no presente estudo, têm sido observadas grandes perdas de $\mathrm{N}$ seja por volatilização de amônia (Costa et al., 1990) ou desnitrificação a oxido nitroso (Carvalho, 2005). Esses fatores explicariam inclusive os menores estoques de NM observados no SPD mucuna em relação ao SPD milheto e SPC milheto, que não diferiram entre si (Quadro 2).

No que se refere ao $\mathrm{N}$ contido na fração particulada da MOS, os dois sistemas sob SPD apresentaram estoques significativamente maiores em relação ao SPC (Quadro 2). A justificativa aqui segue a mesma lógica daquela para COP, onde essa fração, por ser mais sensível ao manejo, depende da proteção estrutural oferecida pela agregação do solo, de modo que no SPC a ação do arado de discos e grade niveladora promove a trituração do material vegetal depositado na superfície e a ruptura dos agregados, expondo a MOS ao ataque microbiano, que também é estimulado pela maior aeração e temperatura do solo observadas nesse sistema (Costa et al., 2003). Assim, observaramse ganhos de NP no SPD em relação ao SPC milheto da ordem de 50,7 e 34,9 \% para SPD milheto e SPD mucuna, respectivamente.

O efeito dos sistemas na biomassa e respiração microbiana - que por consequência altera o acúmulo de MOS - pode ser observado no quadro 4, que apresenta, para a média ponderada da camada de 0 a $20 \mathrm{~cm}$, os valores de $\mathrm{C}$ da biomassa microbiana (CBM), relação CBM:COT, denominada quociente microbiano, respiração microbiana e a relação entre a respiração microbiana e CBM, denominada quociente metabólico.

Observa-se que o CBM foi afetado apenas pelos sistemas, tendo SPD milheto e SPD mucuna apresentado maiores teores em relação ao SPC milheto, mas não diferindo entre si (Quadro 4). Por ser um constituinte do COT, o CBM segue a dinâmica deste, sendo no longo prazo afetado negativamente pelo revolvimento do solo, conforme observaram Granatstein et al. (1987), Mendes et al. (2003) e Figueiredo et al. (2007). 
Quadro 4. Carbono da biomassa microbiana (CBM), quociente microbiano, respiração microbiana e quociente metabólico na camada de 0-20 $\mathrm{cm}^{(1)}$ de um Latossolo Vermelho argiloso cultivado por 11 anos na sucessão soja-milho, sob três sistemas de manejo e duas doses de fósforo

\begin{tabular}{|c|c|c|c|c|c|}
\hline Sistema de manejo & Dose de fósforo & CBM & $\begin{array}{c}\text { Quociente } \\
\text { microbiano }^{(2)}\end{array}$ & $\begin{array}{l}\text { Respiração } \\
\text { microbiana }^{(3)}\end{array}$ & $\begin{array}{c}\text { Quociente } \\
\text { metabólico }^{(4)}\end{array}$ \\
\hline & & $\begin{array}{c}\mathrm{mg} \mathrm{kg}^{-1} \text { de } \\
\mathrm{C}_{\text {mic }} \text { no solo }\end{array}$ & $\%$ & $\begin{array}{c}\mathrm{mg} \mathrm{kg}{ }^{-1} \text { de } \\
\mathrm{C}-\mathrm{CO}_{2} \text { no solo }\end{array}$ & $\begin{array}{c}\mathrm{mg} \mathrm{C}-\mathrm{CO}_{2} \\
\mathrm{mg} \mathrm{C}-\mathrm{CO}_{\mathrm{mic}^{-1}}\end{array}$ \\
\hline SPC milheto & P0 & 261 & 1,5 & 99 & 0,39 \\
\hline SPD milheto & $\mathrm{P0}$ & 370 & 2,0 & 100 & 0,26 \\
\hline SPD mucuna & $\mathrm{P0}$ & 335 & 1,9 & 43 & 0,11 \\
\hline SPC milheto & $\mathrm{P} 100$ & 268 & 1,5 & 128 & 0,53 \\
\hline SPD milheto & $\mathrm{P} 100$ & 367 & 1,9 & 103 & 0,26 \\
\hline SPD mucuna & $\mathrm{P} 100$ & 362 & 1,9 & 79 & 0,22 \\
\hline \multicolumn{6}{|l|}{ Média de sistema } \\
\hline SPC milheto & & $264 \mathrm{~b}$ & $1,5 \mathrm{~b}$ & $113 \mathrm{a}$ & $0,46 \mathrm{a}$ \\
\hline SPD milheto & & $369 \mathrm{a}$ & $1,9 \mathrm{a}$ & $102 \mathrm{~b}$ & $0,26 \mathrm{~b}$ \\
\hline SPD mucuna & & $348 \mathrm{a}$ & $1,9 \mathrm{a}$ & $61 \mathrm{c}$ & $0,16 \mathrm{c}$ \\
\hline \multicolumn{6}{|l|}{ Média de dose } \\
\hline P0 & & $322 \mathrm{a}$ & $1,8 \mathrm{a}$ & $81 \mathrm{~b}$ & $0,25 \mathrm{~b}$ \\
\hline P100 & & 332 a & $1,8 \mathrm{a}$ & $104 \mathrm{a}$ & $0,34 \mathrm{a}$ \\
\hline
\end{tabular}

(1) Média ponderada entre as camadas de 0 a $5 \mathrm{~cm}, 5$ a $10 \mathrm{~cm}$ e 10 a $20 \mathrm{~cm} .{ }^{(2)} \mathrm{CBM} / \mathrm{C}$ orgânico total. ${ }^{(3)}$ Referente a sete dias de incubação. ${ }^{(4)}$ Respiração microbiana/CBM. SPC: sistema de preparo convencional, SPD: sistema plantio direto. P0: 0 e P100: $100 \mathrm{~kg} \mathrm{ha}{ }^{-1}$ ano ${ }^{-1}$ de $\mathrm{P}_{2} \mathrm{O}_{5}$ na forma de superfosfato triplo aplicado no sulco de semeadura. Médias seguidas da mesma letra na coluna não diferem entre si pelo teste de Student $(p<0,05)$.

O quociente microbiano representa a tendência de acúmulo ou perda de C no sistema (Anderson \& Domsch, 1989; Insam, 1990). Diferenças nessa relação em função de sistemas de manejo refletem o padrão de entrada de MOS no solo, a eficiência da conversão do C microbiano, as perdas do C do solo e a estabilização do C orgânico pela fração mineral do solo (Sparling, 1992). Apesar de haver tentativa de determinar um valor de quociente microbiano que represente situações de declínio, equilíbrio ou acúmulo de MOS (Jenkinson \& Ladd, 1981), essa relação apresenta ampla variação na literatura (0,27 a 7,0 \%), principalmente em função de tipo de solo, época de amostragem e método analítico empregado (Anderson \& Domsch, 1989). No presente estudo, o quociente microbiano reafirma o que foi observado para CBM isoladamente com o SPD, apresentando tendência de acúmulo de MOS em relação ao SPC (Quadro 4).

A incapacidade de o CBM diferenciar doses de $\mathrm{P}$ (P0 ou P100), bem como SPD tendo mucuna ou milheto como planta de cobertura (Quadro 4), que apresentaram quantidades de $\mathrm{C}$ adicionadas no solo muito contrastantes (Quadro 3), pode estar relacionada com a própria dinâmica desse parâmetro. Por ser componente da fração mais lábil da MOS, o CBM responde mais rapidamente a mudanças nos padrões de entrada de C no sistema (Silva Filho \& Vidor, 1984; Powlson et al., 1987). Assim, uma vez que a amostragem de solo deste estudo foi realizada no momento de enchimento de grãos da soja, o C adicionado por essa planta pelo sistema radicular ou pela deposição superficial de folhas senescentes, com relação C:N favorável à decomposição microbiana, pode ter proporcionado condição suficiente para igualar o CBM entre os tratamentos P0 e P100, bem como entre os tratamentos com milheto e mucuna sob SPD. Padovan et al. (2006) observaram redução de $23 \%$ da matéria seca de soja cortada no florescimento após 10 dias da adição à superficie do solo, sendo esse valor de $32 \%$ aos 15 dias; e Perez et al. (2004), na camada de $0-5 \mathrm{~cm}$ de uma área cultivada com soja, observaram maior CBM após a colheita, em relação ao momento de floração.

A respiração microbiana foi alterada pela dose de $\mathrm{P}$ e pelos sistemas de manejo (Quadro 4), com P100 apresentando maiores valores em relação à $\mathrm{P} 0$, e os sistemas, a sequência decrescente: $\mathrm{SPC}$ milheto > SPD milheto > SPD mucuna. A maior respiração na dose $\mathrm{P} 100$ em relação à $\mathrm{P0}$ e no SPD milheto em relação à SPD mucuna pode ser justificada pelo maior estoque de COP nesses tratamentos (Quadro 2), caracterizando maior quantidade de substrato aos microrganismos, originada pela maior adição de C (Quadro 3). Na comparação entre SPC milheto e SPD com milheto ou mucuna, o revolvimento do solo foi responsável por promover maior atividade respiratória microbiana, assim como também observaram Matias et al. (2009) em Latossolo Amarelo do cerrado do Piauí, numa área cultivada por quatro anos sob SPD, tendo anteriormente sido conduzida por 20 anos sob SPC, em relação àquela mantida sob SPC.

Resultados semelhantes aos da respiração foram obtidos para a relação entre esse parâmetro e o CBM, denominado quociente metabólico (Quadro 4), que representa a eficiência de uso do C pelos microrganismos do solo (Gama-Rodrigues, 1999). Assim, quando 
a planta de cobertura foi o milheto, a respiração microbiana por unidade de biomassa microbiana no SPD foi $43 \%$ menor em relação ao SPC.

Para Insam \& Domsch (1988), o quociente metabólico diminui em sistemas mais estáveis, e vários trabalhos relatam menores valores de quociente metabólico em SPD (Balota et al., 1998; Matias et al., 2009). Isso ocorre por diversos fatores, como acessibilidade ao substrato, condições físico-químicas do solo ou até mesmo mudanças no padrão metabólico e constituição da biomassa microbiana. No SPD, a manutenção da agregação do solo conferindo proteção estrutural ao COP e o maior tamponamento físicoquímico, com redução nas flutuações de $\mathrm{pH}$, umidade e temperatura (Costa et al., 2003), conduzem à formação de uma comunidade microbiana mais estável, com distribuição equilibrada entre células novas e velhas. Por outro lado, no SPC, as maiores flutuações térmicas e hídricas (Costa et al., 2003), o revolvimento do solo, com quebra de agregados e exposição do COP anteriormente protegido (Hassink \& Whitmore, 1997), além da própria morte celular por efeito direto do arado de discos e grade niveladora, levam à a formação de uma comunidade microbiana mais estressada, que promoverá desvio de energia do crescimento e reprodução para a manutenção celular, de forma que maior proporção de $\mathrm{C}$ será perdida como $\mathrm{CO}_{2}$, resultando em menores estoques de COT e COP, conforme observado no presente estudo no SPC milheto (Quadro 2).

O conteúdo de $\mathrm{C}$ adicionado ao solo que efetivamente passa a compor o COT do solo tem sido estimado em diversos estudos que visam à sua utilização em modelos de predição de variação do COT no solo (Bayer et al., 2000c; Lovato et al., 2004). Essa taxa de conversão, apesar de ser mais precisamente obtida por técnicas isotópicas (Balesdent \& Balabane, 1996), pode ser estimada em experimentos de longa duração a partir da relação entre a adição de $\mathrm{C}$ e as variações nos estoques de COT (Lovato et al., 2004).

No presente estudo, para cada sistema, essa taxa de conversão foi conseguida ao se relacionar a variação do estoque de COT entre os tratamentos P0 e P100 (Quadro 2) com a quantidade de $\mathrm{C}$ adicionada no período do experimento pelas plantas (Quadro 3).

Para SPC e SPD, ambos com milheto como planta de cobertura, o tratamento $\mathrm{P} 100$ adicionou, respectivamente, 43,8 e $37,0 \mathrm{Mg}^{-1} \mathrm{de}^{-1} \mathrm{C}$ a mais em relação ao tratamento P0 (Quadro 3), e o ganho de estoque de $\mathrm{C}$ nesses tratamentos foi de 1,7 e 3,0 $\mathrm{Mg} \mathrm{ha}^{-1}$, respectivamente, para esses dois sistemas (Quadro 2). Assim, para SPC milheto e SPD milheto, houve requerimento de $25,3 \mathrm{Mg} \mathrm{ha}^{-1}$ de $\mathrm{C}(43,8 / 1,7) \mathrm{e}$ $12,2 \mathrm{Mg}^{-1}$ de $\mathrm{C}(37,0 / 3,0)$ para elevar em $1 \mathrm{Mg} \mathrm{ha}^{-1} \mathrm{o}$ COT, significando que a fração de $\mathrm{C}$ adicionado que efetivamente permanece no solo é de 4,0 e 8,2\% para esses dois sistemas, respectivamente. No caso do SPD mucuna, $7,0 \mathrm{Mg} \mathrm{ha}^{-1} \mathrm{de} \mathrm{C}(21,7 / 3,1)$ foram requeridos para elevar em $1 \mathrm{Mg} \mathrm{ha}^{-1}$ o COT, significando que a fração de $\mathrm{C}$ adicionado que efetivamente permanece no solo é de 14,3 \% nesse sistema. Esses valores estão dentro da faixa de 7 a $23 \%$ encontrada na literatura (Bolinder et al., 1999) e são cerca da metade daqueles encontrados por Lovato et al. (2004) no Rio Grande do Sul (12,9 \% no SPD e $11,5 \%$ no SPC), além de apresentar diferenças entre SPD e SPC muito mais acentuadas. Isso ocorre possivelmente pelas maiores temperaturas existentes no Cerrado, resultando em maior atividade microbiana e, por consequência, maior perda de $\mathrm{C}$ antes que ele passe a efetivamente compor o COT do solo.

Na comparação entre SPD mucuna e SPD milheto, as maiores taxas de conversão do $\mathrm{C}$ adicionado em COT do solo podem estar relacionadas à menor taxa de decomposição da mucuna em relação ao milheto, caracterizada pela presença de compostos aromáticos de difícil decomposição, conforme observado por Carvalho et al. (2009), resultando em maior permanência no solo. No entanto, vale ressaltar que, apesar da maior taxa de conversão do $\mathrm{C}$ adicionado em COT do solo, a mucuna produz menos da metade de matéria seca em relação ao milheto (Quadro 3), de modo que no balanço final essa planta de cobertura proporciona menor estoque de $\mathrm{C}$ no solo (Quadro 2). Relacionando as taxas de conversão entre SPD milheto e mucuna, conclui-se que o milheto deverá produzir 1,7 vez mais matéria seca em relação à mucuna para promover o mesmo aumento de COT no solo; no P100 essa relação foi de 2,1 vezes (Quadro 3), justificando os maiores estoques observados no SPD milheto P100 (Quadro 2).

\section{CONCLUSÕES}

1. O sistema plantio direto promove estratificação de $\mathrm{C}$ orgânico e $\mathrm{N}$ total, enquanto o preparo convencional promove distribuição mais homogênea na camada de 0 a $20 \mathrm{~cm}$ de profundidade.

2. A adubação fosfatada por 11 anos promove acúmulo de $\mathrm{C}$ orgânico e $\mathrm{N}$ total em solos com adequada disponibilidade inicial de $\mathrm{P}$, em relação àquele que não recebeu adubação com $P$, independentemente do sistema de preparo e de culturas.

3. Os estoques de $\mathrm{C}$ orgânico e $\mathrm{N}$ total foram maiores no sistema plantio direto em relação ao preparo convencional, ambos tendo o milheto como planta de cobertura, e no milheto em relação à mucuna, ambos sob plantio direto.

4. O sistema plantio direto apresentou maior $\mathrm{C}$ biomassa microbiana e menor respiração microbiana em relação ao sistema de preparo convencional, ambos tendo o milheto como planta de cobertura, e semelhante $\mathrm{C}$ biomassa microbiana e menor respiração microbiana na mucuna em relação ao milheto, ambos sob plantio direto. 
5. A taxa de conversão do $\mathrm{C}$ adicionado pelas culturas em C orgânico do solo foi de 4,0, 8,2 e 14,3 \% para sistema de preparo convencional com milheto, sistema plantio direto com milheto e com mucuna, respectivamente.

\section{AGRADECIMENTOS}

Ao assistente de pesquisa da área de solos da Embrapa Cerrados, Valmir Vieira de Sousa, pela condução das atividades agrícolas do experimento; $\mathrm{e}$ aos técnicos do laboratório de microbiologia dos solos da Embrapa Cerrados, pela ajuda nas análises microbiológicas.

\section{LITERATURA CITADA}

AITA, C.; BASSO, C.J.; CERETTA, C.A.; GONÇALVES, C.N. \& DA ROS, C.O.C. Plantas de cobertura de solo como fontes de nitrogênio ao milho. R. Bras. Ci. Solo, 25:157$165,2001$.

AITA, C.; CERETTA, C.A.; THOMAS, A.L.; PAVINATO, A. \& BAYER, C. Espécies de inverno como fonte de nitrogênio para o milho no sistema de cultivo mínimo e feijão em direto. R. Bras. Ci. Solo, 18:101-108, 1994.

ALVES, B.J.R.; ZOTARELLI, L.; BODDEY, R.M. \& URQUIAGA, S. Soybean benefit to a subsequent wheat cropping system under zero tillage. In: Nuclear techniques in integrated plant nutrient, water and soil management. Vienna, IAEA, 2002. p.87-93.

AMADO, T.J.C.; BAYER, C.; ELTZ, F.L.F. \& BRUM, A.C. Potencial de culturas de cobertura em acumular carbono e nitrogênio no solo no plantio direto e a melhoria da qualidade ambiental. R. Bras. Ci. Solo, 25:189-197, 2001.

ANDERSON, T.H. \& DOMSCH, K.H. Ratios of microbial biomass carbon to total organic carbon in arable soils. Soil Biol. Biochem., 21:471-479, 1989

BALESDENT, J. \& BALABANE, M. Maize root-derived soil organic carbon estimated by natural $13 \mathrm{C}$ abundance. Soil Biol. Biochem., 24:97-101, 1992.

BALESDENT, J. \& BALABANE, M. Major contribution of roots to soil carbon storage inferred from maize cultivated soils. Soil Biol. Biochem., 28:1261-1263, 1996.

BALOTA, E.L.; COLOZZI-FILHO, A.; ANDRADE, D.S. \& HUNGRIA, M. Biomassa microbiana e sua atividade em solos sob diferentes sistemas de preparo e sucessão de culturas. R. Bras. Ci. Solo, 22:641-649, 1998.

BAYER, C. \& MIELNICZUK, J. Dinâmica e função da matéria orgânica. In: SANTOS, G.A. \& CAMARGO, F.A.O., ed. Fundamentos da matéria orgânica: Ecossistemas tropicais e subtropicais. Porto Alegre, Gênesis, 1999. p.9-23.

BAYER, C.; MARTIN-NETO, L.; MIELNICZUK, J. \& CERETTA, C.A. Effect of no-till cropping systems on soil organic matter in sandy clay loam Acrisol from southern Brazil monitored by electron spin resonance and nuclear magnetic resonance. Soil Tillage Res., 53:95-104, 2000a.
BAYER, C.; MARTIN-NETO, L.; MIELNICZUK, J.; PAVINATO, A. \& DIEKOW, J. Carbon sequestration in two Brazilian Cerrado soils under no-till. Soil Tillage Res., 86:237-245, 2006.

BAYER, C.; MIELNICZUK, J. \& MARTIN-NETO, L. Efeito de sistemas de preparo e de cultura na dinâmica da matéria orgânica e na mitigação das emissões de $\mathrm{CO}_{2}$. R. Bras. Ci. Solo, 24:599-607, 2000c.

BAYER, C.; MIELNICZUK, J.; AMADO, T.J.C.; MARTINNETO, L. \& FERNANDES, S.V. Organic matter storage in a sandy clay loam Acrisol affected by tillage and cropping systems in southern Brazil. Soil Tillage Res., 54:101-109, $2000 \mathrm{~b}$.

BERNARDON, T. Componentes da produtividade de grãos de milho (Zea mays L.), visando obter parâmetros para a agricultura de precisão. Santa Maria, Universidade Federal de Santa Maria, 2005. 95p. (Tese de Mestrado)

BOLINDER, M.A.; ANGERS, D.A. \& DUBUC, J.P. Estimating shoot to root rations and annual carbon inputs in soil for cereal crops. Agric. Ecosyst. Environ., 63:61-66, 1997.

BOLINDER, M.A.; ANGERS, D.A.; GIROUX, M. \& LAVERDIÈRE, M.R. Estimating $\mathrm{C}$ inputs retained as soil organic matter from corn (Zea mays L.). Plant Soil, 215:8591, 1999.

BURNS, R.G. Enzyme activity in soil: Location and a possible role in microbial ecology. Soil Biol. Biochem., 14:423-427, 1982.

CAMBARDELlA, C.A. \& ELLIOTT, E.T. Particulate soil organic-matter changes across a grassland cultivation sequence. Soil Sci. Soc. Am. J., 56:777-783, 1992.

CARVALHO, A.M. Uso de plantas de condicionadoras com incorporação e sem incorporação no solo: Composição química e decomposição dos resíduos vegetais; disponibilidade de fósforo e emissão de gases. Brasília, Universidade de Brasília, 2005. 167p. (Tese de Doutorado)

CARVALHO, A.M.; BUSTAMANTE, M.M.C.; ALCANTARA, F.A.; RESCK, I.S. \& LEMOS, S.S. Characterization by solid-state CPMAS 13C NMR spectroscopy of decomposing plant residues in conventional and no-tillage systems in Central Brazil. Soil Tillage Res., 102:144-150, 2009.

CONCEIÇÃO, P.C.; AMADO, T.J.C. \& MIELNICZUK, J. \& SPAGNOLLO, E. Qualidade do solo em sistemas de manejo avaliada pela dinâmica da matéria orgânica e atributos relacionados. R. Bras. Ci. Solo, 29:777-788, 2005.

CORAZZA, E.J.; SILVA, J.E.; RESCK, D.V.S. \& GOMES, A.C. Comportamento de diferentes sistemas de manejo como fonte ou depósito de carbono em relação a vegetação de Cerrado. R. Bras. Ci. Solo, 23:425-432, 1999.

COSTA, F.S.; ALBUQUERQUE, J.A.; BAYER, C.; FONTOURA, S.M.V. \& WOBETO, C. Propriedades físicas de um Latossolo Bruno afetadas pelos sistemas de plantio direto e preparo convencional. R. Bras. Ci. Solo, 27:527535, 2003.

COSTA, F.S.; BAYER, C.; ZANATTA, J.A. \& MIELNICZUK, J. Estoque de carbono orgânico no solo e emissões de dióxido de carbono influenciadas por sistemas de manejo no sul do Brasil. R. Bras. Ci. Solo, 32:323-332, 2008. 
COSTA, F.J.S.A. \& BOULDIN, D.R. Evaluation of N recovery from mucuna placed on the surface or incorporated in a Brazilian Oxisol. Plant Soil, 124:91-96, 1990.

COSTA, S.E.V.G.A.; SOUZA, E.D.; ANGHINONI, I.; FLORES, J.P.C.; CAO, E.G. \& HOLZSCHUH, M.J. Phosphorus and root distribution and corn growth related to longterm tillage systems and fertilizer placement. R. Bras. Ci. Solo, 33:1237-1247, 2009

DIEKOW, J.; MIELNICZUK, J.; KNICKER, H.; BAYER, C.; DICK, D.P. \& KÖGEL-KNABNER, I. Soil C and N stocks as affected by cropping systems and nitrogen fertilization in a Southern Brazil Acrisol managed under no-tillage for 17 years. Soil Tillage Res., 81:87-95, 2005a.

DIEKOW, J.; MIELNICZUK, J.; KNICKER, H.; BAYER, C.; DICK, D.P. \& KÖGEL-KNABNER, I. Carbon and nitrogen stocks in physical fractions of a subtropical Acrisol as influenced by long-term no-till cropping systems and $\mathrm{N}$ fertilization. Plant Soil, 268:319-328, 2005b.

EMPRESA BRASILEIRA DE PESQUISA AGROPECUÁRIA EMBRAPA. Serviço Nacional de Levantamento e Conservação do Solo. Manual de métodos de análise do solo. 2.ed. Rio de Janeiro, 1997. 212p.

FIGUEIREDO, C.C.; RESCK, D.V.S. \& CARNEIRO M.A.C. Labile and stable fractions of soil organic matter under management systems and native Cerrado. R. Bras. Ci. Solo, 34:907-916, 2010.

FIGUEIREDO, C.C.; RESCK, D.V.S.; GOMES, A.C.; FERREIRA, E.A.B. \& RAMOS, M.L.G. Carbono e nitrogênio da biomassa microbiana em resposta a diferentes sistemas de manejo em um Latossolo Vermelho no Cerrado. R. Bras. Ci. Solo, 31:551-562, 2007.

FREIXO, A.A.; MACHADO, P.L.O.A.; GUIMARÃES, C.M.; SILVA, C.A. \& FADIGAS, F.S. Estoques de carbono e nitrogênio e distribuição de frações orgânicas de Latossolo do Cerrado sob diferentes sistemas de cultivo. R. Bras. Ci. Solo, 26:425-434, 2002.

GAMA-RODRIGUES, E.F. Biomassa microbiana e ciclagem de nutrientes. In: SANTOS, G.A. \& CAMARGO, F.A.O., eds. Fundamentos da matéria orgânica: Ecossistemas tropicais e subtropicais. Porto Alegre, Gênesis, 1999. p.227-244.

GRANATSTEIN, K.M.; BEZDICEK, D.F.; COCHRAM, V.L.; ELLIOTT, L.F. \& HAMMEL, J. Long-term tillage and rotation effects on soil microbial biomass, carbon and nitrogen. Biol. Fert. Soils, 5:265-270, 1987.

HASSINK, J. \& WHITMORE, A.P. A model of the physical protection of organic matter in soils. Soil Sci. Soc. Am. J., 61:131-139, 1997.

HERNANI, L.C.; KURIHARA, C.H. \& SILVA, W.M. Sistemas de manejo de solo e perdas de nutrientes e matéria orgânica por erosão. R. Bras. Ci. Solo, 23:145-154, 1999.

INSAM, H. \& DOMSCH, K.H. Relationship between soil organic carbon and microbial biomass on chronosequences of reelamation sites. Microbiol. Ecol., 15:177-188, 1988.

INSAM, H. Are the soil microbial biomass and basal respiration governed by the climatic regime? Soil Biol. Biochem., 22:525-532, 1990
JANTALIA, C.P.; RESCK, D.V.S.; ALVES, B.R.J.; ZOTARELLI, L.; URQUIAGA, S. \& BODDEY, R.M. Tillage effect on C stocks of a clayey Oxisol under a soybean-based crop rotation in the Brazilian Cerrado region. Soil Tillage Res., 95:97-109, 2007.

JENKINSON, D.S \& LADD, J.N. Microbial biomass in soil: Measurement and turnover. In: PAUL, E.A. \& LADD, J.M., eds. Soil biochemistry. NewYork, Marcel Decker, 1981. v.5. p.415-471.

KUSS, R.C.P.; KÖNIG, O.; DUTRA, L.M.C.; BELLÉ, R.A.; ROGGIA, S. \& STURMER, G.R. Populações de plantas e estratégias de manejo de irrigação na cultura da soja. Ci. Rural, 38:1133-1137, 2008.

LOVATO, T.; MIELNICZUK, J.; BAYER, C. \& VEZZANI, F. Adição de carbono e nitrogênio e sua relação com estoques no solo e com o rendimento do milho em sistemas de manejo. R. Bras. Ci. Solo, 28:175-187, 2004.

MATIAS, M.C.B.S.; SALVIANO, A.A.C.; LEITE, L.F.C. \& ARAÚJO, A.S.F. Biomassa microbiana e estoques de $\mathrm{C}$ e $\mathrm{N}$ do solo em diferentes sistemas de manejo, no Cerrado do Estado do Piauí. Acta Sci. Agron., 31:517-521, 2009.

MATSUOKA, M.; MENDES, I.C. \& LOUREIRO, M.F. Biomassa microbiana e atividade enzimática em solos sob vegetação nativa e sistemas agrícolas anuais e perenes na região de Primavera do Leste (MT). R. Bras. Ci. Solo, 27:425-433, 2003.

MENDES, I.C.; SOUZA, L.V.; RESCK, D.V.S. \& GOMES, A.C. Propriedades biológicas em agregados de um Latossolo Vermelho-Escuro sob plantio convencional e direto no Cerrado. R. Bras. Ci. Solo, 27:435-443, 2003.

PADOVAN, M.P.; ALMEIDA, D.L.; GUERRA, J.G.M.; RIBEIRO, R.L.D.; OLIVEIRA, F.L.; SANTOS, L.A.; ALVES, B.J.R. \& SOUTO, S.M. Decomposição e liberação de nutrientes de soja cortada em diferentes estádios de desenvolvimento. Pesq. Agropec. Bras., 41:667-672, 2006.

PEREZ, K.S.S.; RAMOS, M.L.G. \& McMANUS, C. Carbono da biomassa microbiana em solo cultivado com soja sob diferentes sistemas de manejo nos Cerrados. Pesq. Agropec. Bras., 39:567-573, 2004.

POWLSON, D.S.; BROOKES, P.C. \& CHRISTENSEN, B.T. Measurement of soil microbial biomass provides an early indication of changes in the total soil organic matter due to straw incorporation. Soil Biol. Biochem., 19:159-164, 1987.

SILVA FILHO, G.N. \& VIDOR, C. As práticas de manejo do solo na população microbiana. R. Bras. Ci. Solo, 28:291296, 1984

SILVA, V.R.; REINERT, D.J. \& REICHERT, J.M. Densidade do solo, atributos químicos e sistema radicular de milho afetados pelo pastejo e manejo do solo. R. Bras. Ci. Solo, 24:191-199, 2000

SISTI, C.P.J.; SANTOS, H.P.; KOHHANN, R.; ALVES, B.J.R.; URQUIAGA, S. \& BODDEY, R.M. Change in carbon and nitrogen stocks in soil under 13 years of conventional or zero tillage in Southern Brazil. Soil Tillage Res., 76:39-58, 2004. 
SOUSA, D.M.G. \& LOBATO, E., ed. Cerrado: Correção do solo e adubação. 2.ed. Planaltina, Embrapa Cerrados, 2004. $416 \mathrm{p}$.

SOUSA, D.M.G.; REIN, T.A.; GOEDERT, W.J.; LOBATO, E. \& NUNES, R.S. Fósforo. In: PROCHNOW, L.I.; CASARIN, V. \& STIPP, S.R., eds. Boas práticas para uso eficiente de fertilizantes: Nutrientes. Piracicaba, IPNI, 2010. v.2. p.67132 .

SPAGNOLLO, E.; BAYER, C.; WILDNER, L.P.; ERNANI, P.R.; ALBUQUERQUE, J.A. \& PROENÇA, M.M. Leguminosas estivais intercalares como fonte de nitrogênio para o milho no Sul do Brasil. R. Bras. Ci. Solo, 26:417-423, 2002.

SPARLING, G.P. Ratio of microbial biomass carbon to soil organic carbon as a sensitive indicator of changes in soil organic matter. Austr. J. Soil Res, 30:195-207, 1992.
VANCE, E.D.; BROOKES, P.C.; JENKINSON, D.S. An extraction method for measuring soil microbial biomass C. Soil Biol. Biochem.,, 19:703-707, 1987.

VIEIRA, F.C.B.; BAYER, C.; ZANATTA, J.A.; DIECKOW, J. \& MIELNICZUK, J. Carbon management index based on physical fractionation of soil organic matter in an Acrisol under long-term no-till cropping systems. Soil Tillage Res., 96:195-204, 2007.

WAISEL, Y.; ESHEL, A. \& KAFKAFI, U., eds. Plant roots the hidden half. 3.ed. New York, Marcel Dekker, 2002. 1136 .

WEBER, M.A. \& MIELNICZUK, J. Estoque e disponibilidade de nitrogênio no solo em experimento de longa duração. R. Bras. Ci. Solo, 33:429-437, 2009. 
